\title{
Climate change in East and Central Asia associated with the uplift of the Tibetan Plateau-A simulation with the MRI coupled atmosphere-ocean GCM
}

\author{
Manabu Abe†*, Tetsuzo Yasunarił and Akio Kitoh\$ \\ † Graduate School of Environmental Studies, Nagoya University, Nagoya, 464-8601, JAPAN \\ $\ddagger$ Hydrospheric Atmospheric Research Center, Nagoya University, Nagoya, 464-8601, JAPAN \\ $\$$ Meteorological Research Institute, Tsukuba, 305-0052, JAPAN \\ *To whom correspondence should be addressed.E-mail:mabe@hyarc.nagoya-u.ac.jp
}

The Tibetan plateau has significant roles in the formation of the Asian monsoon circulation. The effect of the Tibetan plateau on the Asian monsoon circulation has been investigated using the atmospheric general circulation model (AGCM) (e.g., Hahn and Manabe 1975, An et al. 2001). Also, Broccoli and Manabe (1992) investigated the role of the Tibetan plateau on the formation of the mid-latitude dry climate in Central Asia, using AGCM. In their study, while the moist climate is formed in South and East Asia, the dry climate appears in the northwest of the Tibetan plateau due to its existence. Thus, their result makes us recognize that the Tibetan plateau does not affect the climate only in moist climate, such as South and East Asia, but also in dry climate, such as Central Asia. Further, because the oceanic changes associated with the uplift of the large-scale orography, which is shown in Abe et al. (2003, 2004), affects the climate in Asia, changes in the oceanic circulation should be considered in the experiments to study the effect of the orography on formation of the climate. In order to investigate the climate change due to the progressive uplift of the large-scale orography, an experiment considering changes in the oceanic circulation was conducted using the Meteorological Research Institute (MRI) coupled atmosphere-ocean general circulation model I (CGCM-I). In this presentation, the climate change in East and Central Asia is focused on.

Our experiment has six runs, and in the runs which, individually, were called M0, M2, M4, M6, M8, and M, six different elevations of the global mountain, which are $0,20,40$, 60,80 , and $100 \%$ of the present standard mountain height, were used, respectively. Land-sea distribution is the same in all runs. All the runs were integrated for 50 years, separately, and the data for the last 30 years (21-50) were used in our analyses. The MRI CGCM-I is the global grid model. Horizontal resolution of atmospheric part of the CGCM is $5^{\circ}$ in longitude and $4^{\circ}$ in latitude, and the vertical is 15 layers. The oceanic part has nonuniform meridional resolution ranging from 0.5 to $2.0^{\circ}$, with a finer grid in the tropics, fixed zonal resolution of $2.5^{\circ}$, and 21 layers vertically. The original model predicts sea ice concentration and thickness, but for our experiments fixed monthly sea ice conditions based on observations, were prescribed for all the runs.

In summer (June, July and August), the southwesterlies at low-level from South through East Asia are enhanced with the uplift of the Tibetan Plateau, and the region of the great precipitation in moist Asia also migrates into the interior of the land. At the upper level in the troposphere, the anticyclonic circulation appears over the Tibetan Plateau and become stronger, as the Tibetan plateau becomes higher. The summer precipitation in East Asia increases gradually from M0 to M8, because the moisture transported by the southwesterlies increases, but the increase from M8 to M is not found. These increased rates are larger in the lower stages from M0 to M6 than the higher stages from M6 to M (Abe et al. 2003). These changes are also related to the enhancement of the subtropical high over the North Pacific with the uplift of the global orography, and the region of great precipitation in East Asia moves into the interior as the subtropical high expands into the East Asia. Further, because the moisture transported from the western Pacific is also increases due to the enhancement of the trade wind and the warm pool in the western Pacific appears with the uplift of the Tibetan plateau (Abe et al. 2004), these influences should be connected with the summer monsoon climate in Southeast and East Asia. Kitoh (2004) conducted the same experiment using the new MRI coupled GCM (MRI CGCM-II). His study shows the appearance of the Baiu-front over around Japan associated with the uplift of the Tibetan plateau, which is related to the appearance of the warm pool in the western Pacific and the increase in moisture transported from western Pacific. In winter (December, January, and February), the westerlies in M0 in East Asia change to the northwesterlies in $\mathrm{M}$ due to the uplift of the Tibetan plateau, although the wind velocity shows small change.

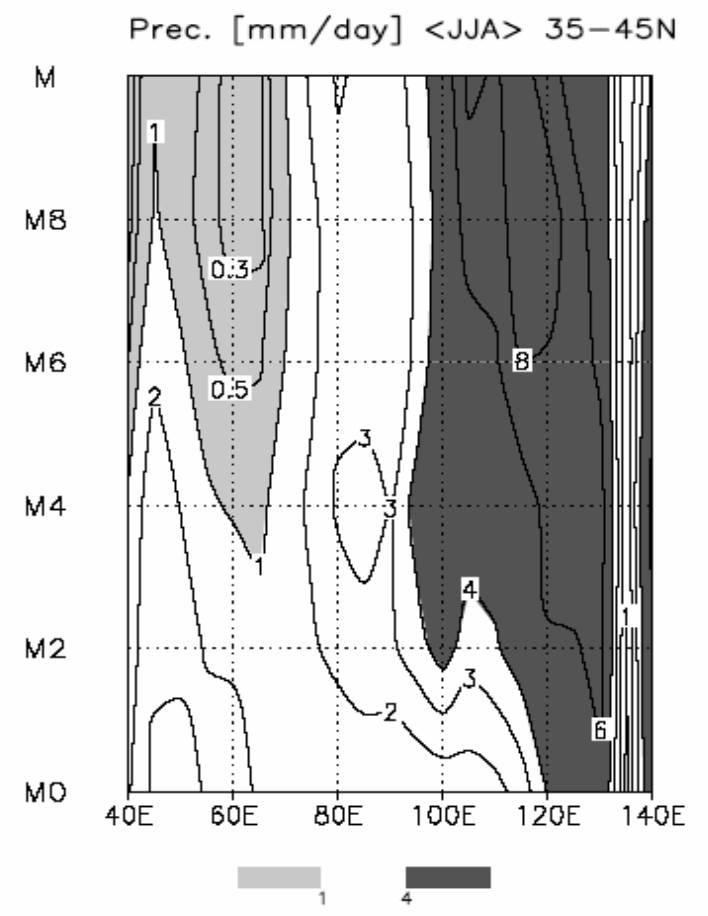

FIGURE 1. The changes in summer precipitation, averaged $35^{\circ}-45^{\circ} \mathrm{N}$, with the uplift of the Tibetan plateau. Unit is $\mathrm{mm}$ per day. 
Dry climate region is found the west of the Tibetan plateau in the lower stages (M2 and M4). In the higher stages, the dry climate expanded clearly to the northwest of the Tibetan plateau and Central Asia. In Central Asia, summer precipitation in Central Asia decreases gradually with the uplift of the Tibetan plateau and that below $1 \mathrm{~mm}^{\text {day }}{ }^{-1}$ appears in M4 (Figure 1). The region of great precipitation in East Asia expands significantly to the interior of the land in the lower stages from M0 to M4. From M4 to M6, however, retreat of the expansion of the greater precipitation region is found, as shown in Figure 1. In the higher stages from M6 to M, the precipitation decreases gradually. Further, no expansion of the greater precipitation region to Central Asia is found as if the appearance of the dry climate region begins to prevent the greater precipitation region in East Asia from expanding west, although precipitation in East Asia increases.

\section{References}

Abe M, A Kitoh and T Yasunari. 2003. An evolution of the Asian summer monsoon associated with mountain uplift -simulation with the MRI atmosphere-ocean coupled GCM-. J Meteor Soc Japan 81: 909-33

Abe M, T Yasunari and A Kitoh. 2004. Effects of large-scale orography on the coupled atmosphere-ocean system in the tropical Indian and Pacific oceans in boreal summer. J Meteor Soc Japan 82: 745-59

An Z-S, JE Kutzbach, WL Prell and SC Porter. 2001. Evolution of Asian monsoon and phased uplift on the Himalayan-Tibetan plateau since late Miocene times. Nature 41: 62-6

Broccoli AJ and S Manabe. 1992. The effects of orography on middle latitude northern hemisphere dry climate. J Climate 5: 1181-201

Hahn DG and S Manabe. 1975. The role of mountains in the south Asian monsoon circulation. J Atmos Sci 77: 1515-41

Kitoh A. 2004. Effects of mountain uplift on East Asian summer climate investigated by a coupled atmosphere-ocean GCM. J Climate 17: 783802 